had been a significantly higher mortality compared with men of the same age and in the same locality due to cardiorespiratory failure and bronchial carcinoma. Reduction of cigarette smoking, declining atmospheric pollution, and antibiotic treatment had all led to reduction in the 24-hour sputum volume in these patients. The initial $\mathrm{FEV}_{1}$ was significantly lower in those patients who later died from cardiorespiratory failure. Indeed, when the $\mathrm{FEV}_{1}$ was $70 \%$ or more of the predicted normal value the prognosis was nearly that of the population at large, but where it fell to $50 \%$ or less of the predicted normal value there was a considerable mortality. The duration of antibiotic treatment and the smoking record did not significantly affect the decline in $\mathrm{FEV}_{1}$ with advancing age, but the diffusing capacity for carbon monoxide had declined more in those who continued to smoke. Thus giving up smoking in patients with advanced obstructive bronchitis does not appear to improve the prognosis-but there is good reason to suppose that it reduces the incidence of bronchial carcinoma.

${ }^{1}$ Medical Research Council, Lancet, 1965, 1, 775.

2 Thurlbeck, W M, et al, Medicine, 1970, 49, 81.

3 Oswald, N C, Harold, J T, and Martin, W J, Lancet, 1953, 2, 639.

4 Palmer, K N V, British Medical fournal, 1954, 1, 1473.

5 Royal College of Physicians, Air Pollution and Health. London, Pitman, 1970.

${ }^{6}$ Lowe, C R, Proceedings of the Royal Society of Medicine, 1968, 61, 98.

7 May, J R, The chemotherapy of Chronic Bronchitis and allied disorders, 2nd ed. London, English Universities Press, 1972.

${ }^{8}$ Eriksson, S, Acta Medica Scandinavica, 1964, 175, 197.

9 British Medical fournal, 1966, 1, 101.

10 Howard, P, British Medical fournal, 1974, 2, 89.

11 Doll, R, and Hill, A B, British Medical fournal, 1964, 1, 1399.

12 Medici, T C, and Buergi, H, American Review of Respiratory Disease, 1971, 103,784 .

13 Medical Research Council, British Medical fournal, 1966, 1, 1317.

14 Johnston, R N, et al, British Medical fournal, 1969, 4, 265.

15 Malone, D N, Gould, J C, and Grant, I W B, Lancet, 1968, 2, 594.

16 Oswald, N C, Medvei, V C, and Waller, R E, Thorax, 1967, 22, 279.

17 Burrows, B, and Earle, R H, New England Fournal of Medicine, 1969, 280, 397.

18 Bates, D V, American Review of Respiratory Disease, 1973, 108, 1043.

19 Johnston, R N, et al, Thorax, 1976, 31, 25.

\section{African trypanosomiasis}

In Africa human trypanosomiasis is caused by protozoa of the genus Trypanosoma and is transmitted by species of Glossina, the tsetse fly. The clinical picture may be one of the polar forms of the disease-Gambian or Rhodesian sleeping sickness-or may be intermediate. In West Africa the tsetse fly needs shade and moisture and lives along the banks of rivers, whereas in the east the flies seem able to live in open country. The source of infection is man, with symptomatic or asymptomatic disease, with trypanosomes in his blood; where the Rhodesian disease is prevalent some varieties of wild game may be a further reservoir but their importance depends on the game-fly-man contact. ${ }^{1}$ The Gambian disease is found most often in West Africa and in Zaire, which has the higher incidence at present: it has a long incubation period (making the individual a source of infection for longer) and causes a chronic illness. By contrast, the Rhodesian form of trypanosomiasis has a shorter incubation period and causes a more acute illness.

Trypanosomiasis may be controlled by reducing the size of the pool of infection or by reducing the numbers of fly vectors in contact with man, or both. Regular examination of the human population-for example, at six-month intervals-and treatment of those infected will reduce the sources of infection. A single intramuscular dose of pentamidine isethionate (300$400 \mathrm{mg}$ ) every six months will keep the blood free of parasites and protect against the Gambian but not the Rhodesian disease. ${ }^{2}$ Control of the vector has mainly depended on insecticides and other measures such as clearing river banks -the habitat of riverine species of tsetse fly.

In West African foci of the Gambian disease the local populations are under regular medical supervision so that the problem is stable; surprise outbreaks do, however, occur (as in Mali in 1973, when 388 cases were reported). Regular screening by blood films is costly and time-consuming, and serological diagnostic techniques have been introduced. ${ }^{34}$ The blood of infected patients can usually be cleared of trypanosomes by treatment with suramin, which must be given intravenously and has side effects. When there is invasion of the nervous system the arsenical melarsoprol, less toxic than the original tryparsamide but still toxic, is required; again it must be given parenterally.

Tsetse flies have been eradicated from large parts of Northern Nigeria and elsewhere by insecticides, but there is always the possibility of reintroduction unless adequate surveillance is continued. Riverine species of Glossina are more difficult to control, and insecticides are being sought which can be applied at very low concentrations by air and which have a wide margin of safety for animals.

In parts of Africa in the last decade control of trypanosomiasis has lapsed, with an increase in the human prevalence rate; an example is Zaire, where in 1958 the prevalence was $0.02 \%$ but in 1964 was $15 \%$-after six years during which the surveillance and treatment system did not function; under similar circumstances there was a recrudescence of sleeping sickness in the Sudan. Population movements may also upset previous stability, and an increase in prevalence may follow the movement of people away from areas of drought.

Control by regular human case finding and by attack on the vector needs personnel and money. Recently the United Nations Development Project (UNDP), with the support of 19 African countries, has started an applied research programme concerned with both of these means of control and with training personnel; it is linked with a parallel project under the auspices of the Food and Agriculture Organisation (FAO) concerned with the control of trypanosomiasis in animals, a disease responsible for severe economic loss. ${ }^{5}$

${ }^{1}$ Apted, F I C, et al, fournal of Tropical Medicine and Hygiene, 1963, 66, 1. 2 Willett, K C, in Medicine in the Tropics, ed A W Woodruff, p 75. Edinburgh, Churchill Livingstone, 1974.

${ }^{3}$ Binz, G, Bulletin of the World Health Organisation, 1972, 47, 773.

4 Cunningham, M P, Bailey, N M, and Kimber, C D, Transactions of the Royal Society of Tropical Medicine and Hygiene, 1967, 61, 688.

5 World Health Organisation, Weekly Epidemiological Record, 1976, 51, 21.

\section{Treatment of erectile impotence}

The "new sex therapy" has become a therapeutic vogue, big business in the United States with a growing demand in Britain. As with many forms of treatment, particularly those based on psychological mechanisms, requests for it and the optimism of the therapists have leapt ahead of real evidence of effectiveness. It is only too easy for the efficacy of a specific 